\title{
Characterization of Nanosilica and Comparing Its Effect on Crude Oils and Diesel Fuel
}

\author{
Adnan A. Ateeq ${ }^{1}$, Khalid A. Sukkar², Murtadha AbdAl-Huassein ${ }^{1}$ \\ ${ }^{1}$ Basrah Engineering Technical College/ Southern Technical University-Basra-Iraq \\ ${ }^{2}$ Chemical Engineering Department/ University of Technology-Baghdad-Iraq \\ *Email: betc@stu.edu.iq
}

\begin{abstract}
Heavy oils generally exhibit high viscosity, which is detrimental to their production, transport, and refining. The Oil \& Gas industry has thoroughly investigated the use of chemical agents to improve the mobility of this type of low-quality crude oils at the surface as well as reservoir conditions for many years. In this sense the main objective of this work is to investigate the viscosity reduction of heavy oil resulting from the presence of silica nanoparticles by asphaltene adsorption process. Silica nanoparticles was produced successfully in this work from sand of Mount Sannam in Basra city (south of Iraq) by chemical and physical methods $\left(\mathrm{SiO}_{2}\right.$ ch and $\mathrm{SiO}_{2}$ ph respectively). The XRD results indicated a high purity $\mathrm{SiO}_{2 \text { ch }} \mathrm{NPs}$ was produced with purity of $96.8 \%$, while, the purity of $\mathrm{SiO}_{2 \text { ph }} \mathrm{NPs}$ was about $87.2 \%$. The main particle size analyzer (PSA) were measured to be $35 \mathrm{~nm}$ and $22 \mathrm{~nm}$ for $\mathrm{SiO}_{2 \mathrm{ch}} \mathrm{and} \mathrm{SiO}_{2 \mathrm{ph}}$ respectively. On the other hand, the BET total surface area of $\mathrm{SiO}_{2 \mathrm{ch}}$ and $\mathrm{SiO}_{2 \mathrm{ph}} \mathrm{NPs}$ were $520 \mathrm{~m}^{2} / \mathrm{g}$ and $705 \mathrm{~m}^{2} / \mathrm{g}$ respectively. Also, the SEM results showed a uniform distribution of nanoparticles for both prepared silica nanoparticles. The FTIR results indicated a high intensity bonds were formed due to present of functional groups of Si-O-Si, O-Si-O and Si-O. Two Iraqi crude oil samples was selected to be as base fluid with APIs (17.4 and 29.1). Also, diesel fuel with API= 40.91 was tested. For each hydrocarbon a nanofluid was prepared by adding silica nanoparticles to parent fluid. Four concentration of silica nanoparticles were added to the parent fluid (250, 500, 1000 and $1250 \mathrm{mg} / \mathrm{L}$ ). And also, used a bath ultrasonic method for dispersing NPs inside the parent oils.
\end{abstract}

Keywords: Petroleum Pipelines; natural nanoparticles; viscosity reduction; silica preparation; silica characterization; asphaltene adsorption; crude oil

DOI: $10.7176 / \mathrm{JNSR} / 9-4-08$

\section{Introduction}

The world's reserves of crude oil amount to $30 \%$ in conventional and $70 \%$ in non-conventional reservoirs, respectively. Among the non-conventional type, heavy oil (HO) and extra-heavy oil (EHO) represent almost $25 \%$ and $45 \%$ of these resources, respectively. However, the production, transport and refining of $\mathrm{HO}$ and EHO represent a considerable set of technological challenges. The main challenging characteristics of these crude oils, namely their high specific gravity and high viscosity, complicate their production, transport and refining. These types of crude oils are characterized by containing large concentrations of heavy metals and heteroatoms, and heavy compounds such as asphaltenes, as well as low $\mathrm{H} / \mathrm{C}$ ratio, which directly influence the observed crude oil viscosity, typically higher than $100 \mathrm{cP}$ at reservoir conditions. In crude oil markets, there are many classifications for the crude oils depending on their nature and compositions. One of the most general categories for crude oil is depend on the American Petroleum Institute Gravity (API) as shown in table 1. The properties may changes according to proportion of sulfur content, hydrocarbon elements etc. Also, the geographical locations from which the crude oils are extracted. In petroleum sector there are many techniques are used for transportation of crude oils such as: truck transport, oil tankers over the seas, rail transportation, and pipelines. Among all these techniques, the transportation of crude oils through pipeline is regards more favorable because of its high safe, efficiency and work in many different environments, including forest, mountain ranges and ocean floor. There are many techniques used for enhancing mobility of crude oils via transportation pipeline in which grouped into two types namely viscosity reduction techniques and drag reduction techniques. The viscosity reduction techniques are environmentally and economically characterized by the high cost. This type of techniques included the dilution techniques, thermal techniques, emulsification of oil in water $(\mathrm{O} / \mathrm{W})$ emulsions, deasphalting oil by using $\mathrm{CO}_{2}, \mathrm{n}$ alkanes of low and high molecular weight and in-situ upgrading such as the different modes of air injection, for example, in-situ combustion (ISC) [1,2]. The use of drag reducing agents seeks to decrease friction close to the pipe walls to stop the increasing of turbulence by absorbing the energy discharged within the lamellar layer. The main strategies of drag reduction methods including the use of some additives (i.e. polymers and surfactant) and 
use of annular flow technique.

Table 1. Classification of crude oil depending on API gravity

\begin{tabular}{|l|l|}
\hline $\begin{array}{l}\text { Crude Oil Type } \\
\text { Light }\end{array}$ & $\begin{array}{l}\text { API Gravity } \\
\text { Larger than } 31.1^{\circ}\end{array}$ \\
\hline Medium & Between $22.3^{\circ}$ and $31.1^{\circ}$ \\
\hline Heavy & Smaller than $22.3^{\circ}$ \\
\hline
\end{tabular}

Recently, Mortazavi-Manesh and Shaw [3] studied the influence of various chemical compounds on the rheological characteristics of Maya crude oil at different temperatures. In their study, the compounds used were toluene, nheptane and a 50/50 vol\% mixture of toluene and butanone. The rheological evaluation was done using steadystate technique with share rates $0-200 \mathrm{~s}^{-}{ }^{1}$; as expected, when the temperature and dilution increase the viscosity of oil reduced. In recent years, nanotechnology has used as a very good technique for flow characteristics enhancement of crude oil through pipelines in comparison with conventional techniques. Nanotechnology refers to the technology that deals with material in $10^{-9}$ from meter scale. Nanoscience describes the phenomenon and also the behavior of materials at nano-scale size, whereas nanotechnology states the planning, characterization, production and application of materials at nanoscale. It is well-known that the nanomaterials are any materials have nano-scales in their structures. While, nanoparticles are materials have dimensions with the range of 1 to 100 $\mathrm{nm}$. Therefore many researchers [4-6] have demonstrated the ability of nanoparticles to reduce viscosity and increase the mobility of heavy oil at reservoir conditions as tested at both laboratory [7] and field scales [8]. It has been observed that $\mathrm{SiO}_{2}$ nanoparticles are able to reduce the viscosity of heavy oil to a greater degree than other nanomaterials, which has been mainly attributed to high adsorptive capacities of asphaltenes that lead to the reduction of its mean aggregate size and consequently to the perturbation of the viscoelastic network formed [7]. Based on the Einstein's theory [36] in which states that, by adding solid particles to a liquid, the viscosity of liquid would increase proportional to the volume fraction of solid particles added. The classical Einstein's theorem doesn't justify the crude oil behavior once it's been contacted with nanoparticles because the interactions between nanoparticles and heavy molecules in the crude oil such as asphaltenes. This behavior will produce fragmentation of high molecular weight flocs. The existence of such fragmentation, a redistribution of aggregates asphaltenes stay within the liquid to be smaller, bonds breaking forming the viscoelastic large network and preventing additional formation as shown in figure.1. It is well-known that when attractive binding energy is reduced the viscosity decreases. This will be causes a decreasing in the cohesive forces of the crude oil molecular components will be occur. At low operating temperatures some components of crude oil behave like solids. Thus, in these cases the viscosity of the system will depend upon their alignment or breakage. The most polar molecules exist in crude oil after fragmentation process is the asphaltenes. The subsequent step or Phenomenon will occur is that the asphaltenes will adsorbed on nanoparticles surfaces. Figure. 2 shows the adsorption process of asphaltenes on nanoparticles surfaces. The process of asphaltenes adsorption on the surfaces of nanoparticle will decrease the ability of the asphaltic compounds to interact with each other. Then, from an engineering and economical point of view, the money consumed in oil production and transportation will be decreased by eliminate of asphaltenes from crude oil. This conclusion is further confirmed by results gained when nanoparticles were added to de-asphalted oil (DAO) and for light oil (LO) with low content of asphaltene; in either cases the viscosity increases. These results stated that the nanoparticles interact directly with asphaltenes present in crude oil. Many authors noted that the existence of asphaltenes in crude oils at high percentage above $5 \mathrm{wt} \%$, the asphaltenes configuration is formed by a series of clusters of nanoaggregates, forming a large size of viscoelastic network. Then, it was noted that the addition of nanoparticles to the crude oil will be decrease both yield stress and viscosity. Therefore, in practical terms, such behavior translates into the stress required to start flow of crude oil. 
Table 2. Properties of the selected Basra crude oil.

\begin{tabular}{|l|l|l|l|l|l|l|}
\hline \multirow{2}{*}{$\begin{array}{l}\text { The } \\
\text { Sample }\end{array}$} & Sode & $\begin{array}{l}\text { Specific } \\
\text { Gravity }\end{array}$ & API $^{\circ}$ & $\begin{array}{l}\text { Water } \\
\text { Content } \\
\text { Vol \% }\end{array}$ & $\begin{array}{l}\text { Bs \& } \\
\text { W } \\
\text { Vol \% }\end{array}$ & \multicolumn{2}{|l|}{ Salt Content } \\
\cline { 5 - 8 } & 9448 & 17.4 & 28 & 30 & 19169 & 54689 \\
\hline $\mathrm{C}_{1}$ & 8913 & 29.1 & - & - & - & - \\
\hline $\mathrm{C}_{2}$ & ASTM 7777 & $\begin{array}{l}\text { ASTM } \\
4006\end{array}$ & $\begin{array}{l}\text { ASTM } \\
4007\end{array}$ & \multicolumn{2}{|l|}{ IP-77 } \\
\hline $\begin{array}{l}\text { Standard } \\
\text { Method }\end{array}$ & \multicolumn{2}{|c|}{ ASTM } \\
\hline
\end{tabular}

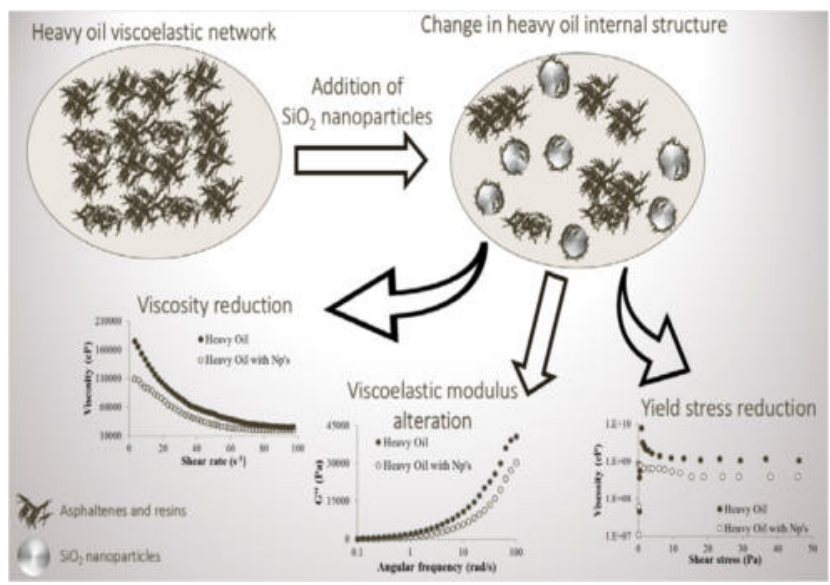

Figure 1. The interaction of nanoparticles with

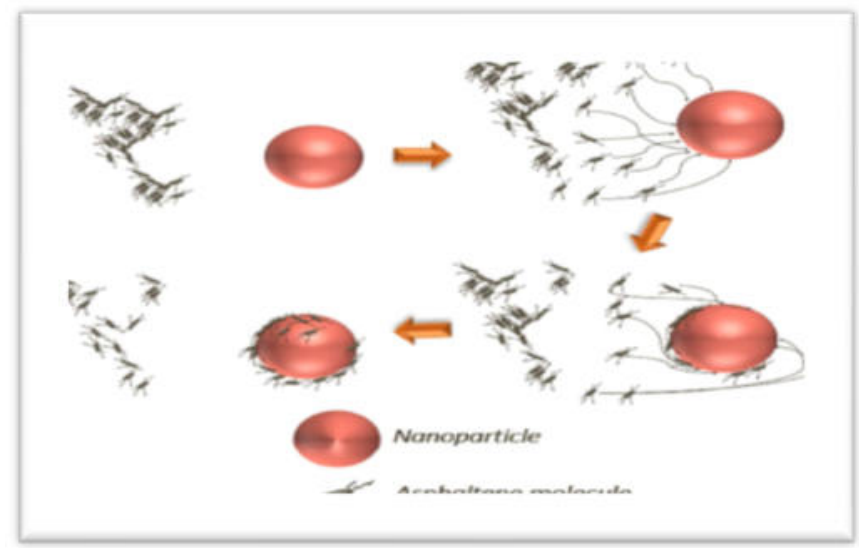

Figure 2. Adsorption process of asphaltenes on nanoparticles surfaces asphaltenes

\section{Experimental work}

\subsection{Materials}

Many materials were used in the present work. The main one is the sand raw material bring it from Sannam Mountain in Basra city (south of Iraq). The sand was taken on the depth of $60 \mathrm{~cm}$ to be sure is clear from contaminants. Other chemicals were purchased (fluke company) such as $\mathrm{NaOH}(99 \%), \mathrm{HCl}(1 \mathrm{M})$ and $\mathrm{H}_{2} \mathrm{SO}_{4}(5 \mathrm{M})$. 
In addition,

\subsubsection{Base fluids}

Two Iraqi crude oils was used as a base fluid for viscosity reduction tests. The crude oils were selected with different API gravities. Table 2 shows the properties of the selected crude oils. On the other hand, a diesel fuel was selected as a light hydrocarbon fraction in which have no asphaltenes in its structure. This fuel is selected to study its viscosity and compare it with crude oil behavior.

\subsubsection{Silica NPs Production Methods}

\subsubsection{Production of Silica Nanoparticles by Chemical Method}

Silica nanoparticles are produced by chemical method by using the Basra sand from Sannam Mountain in south of Iraq.

The grain size of sand particles were in the range of 0.1 to $2 \mathrm{~mm}$.

Then, the following procedure was applied to produce silica NPs by using chemical method:

1- Mixing of $10 \mathrm{~g}$ of sand raw material with $\mathrm{NaOH}(3 \mathrm{M})$ in stirred refluxing unit of $500 \mathrm{ml}$ for 24 hours. The refluxing unit contain a condenser.

2- The system was heated to a constant temperature of $100^{\circ} \mathrm{C}$.

3- The sand silica was dissolved and sodium silicate was produced.

4- The produced slurry was then filtered by using (No.41) filter paper followed by washing with hot distilled water.

5- When the $\mathrm{pH}$ of solution was reached to about 10 , the silica was precipitated.

6- A silica gel was formed in this stage then the solution was treated with (5M) $\mathrm{H}_{2} \mathrm{SO}_{4}$ to reach neutralization of $\mathrm{pH}$ equal 7 with stirring.

7- The produced material was then stand for 24 hours at $25^{\circ} \mathrm{C}$.

8- Then, the product was filtered and washed to remove any salts by using distilled water.

9- The residue material was dried at $110^{\circ} \mathrm{C}$ over night.

10- In order to increase the purity of silica the solid product was refluxed with a $(1 \mathrm{M})$ of hydrochloric acid at temperature of $110^{\circ} \mathrm{C}$ for two hours.

11- The suspension was filtered and washed with distilled water, and then, dried at temperature of $110{ }^{\circ} \mathrm{C}$ overnight.

12- Then, the final product was calcinied at $800{ }^{\circ} \mathrm{C}$ for 2 hours by using a muffle furnace. Then, a high pure nanosilica $(96 \%)$ was obtained.

\subsubsection{Production of Silica Nanoparticles by Physical Method}

The production of silica nanoparticles was produced in this method by using milling techniques. This technique is one of the most famous method to prepare a huge amounts of fine materials in micro or nano scales. It is may be used for milling all kinds of materials. This techniques is based on the philosophy of nanomaterial production (from top-down).

The milling process included the following stages:

1- The sand raw material was pretreated by washing with distilled water to remove the dust and impurities followed by filtration.

2- Then, the washed sand was dried to temperature of $110^{\circ} \mathrm{C}$ over night.

3- A primary milling process was used to reduce the particles size of the sand. Where, a $10 \mathrm{~g}$ of sand raw material was milled in a micro milling machine for 2 hours.

4- The micro milled sand particles was then milled in a nano milling machine for 4 hours. The milling machine held in Nanotechnology \& Advanced Materials Research Center/ University of Technology in Baghdad. 


\section{Results and Discussion}

\subsection{Characterization of Prepared Nanosilica}

The specifications of prepared nanosilica are characterized by many specification techniques as following:

\subsubsection{SEM Results}

The Scanning Electron Microscope (SEM) images in figure (3) illustrate morphology, size and distribution of the prepared silica nanoparticles by chemical and physical methods at different magnifications. It can be seen that the nanosilica particles with various structures including irregular form particles, spherical particles and also agglomerates because action of constricting of the ball-milling technique. The Van-der-Waal forces effect between the separated particles is the reason of this strong trending for agglomeration which subsists within the particles. These results are in good agreement with the results obtained by Wahyudia et al. [9].

(a)
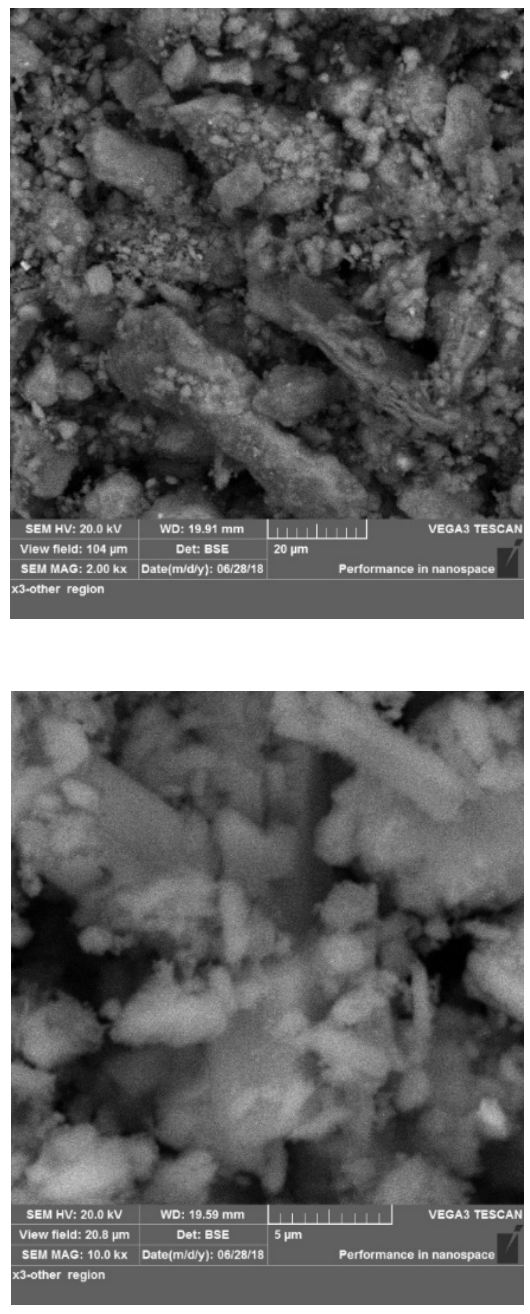
(b)
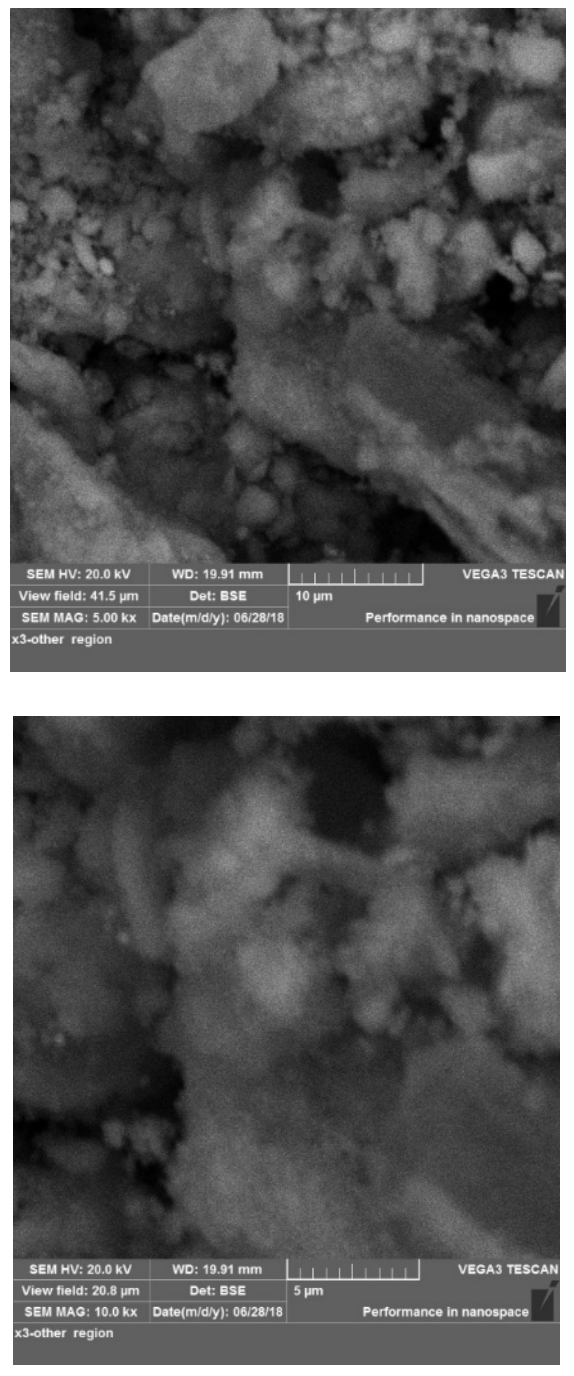

Figure 3. SEM results of prepared nanosilica by (a) chemical method and (b) physical method at different magnifications.

\subsubsection{BET Results}

The specific surface area (SSA) of the produced silica nanoparticles is found by the (BET) technique. The total surface area of $\left(\mathrm{SiO}_{2}\right)_{\mathrm{ch}}$ and $\left(\mathrm{SiO}_{2}\right)_{\mathrm{ph}} \mathrm{NPs}$ were $520 \mathrm{~m}^{2} / \mathrm{g}$ and $705 \mathrm{~m}^{2} / \mathrm{g}$ respectively. The group of smaller particle size has higher surface area than other groups. These results are in good agreement with the results obtained by Quercia et al. [10].

\subsubsection{PSA Results}

The silica nanoparticles obtained were determined by (PSA) particle size analyzer. Two different groups of silica nanoparticles samples were analyzed, the range of first group $\left(\mathrm{SiO}_{2}\right)_{\mathrm{ch}}$ was $(45-23) \mathrm{nm}$, and the higher volume percent of particle size was $35 \mathrm{~nm}$. The range of second group $\left(\mathrm{SiO}_{2}\right)_{\mathrm{ph}}$ was $(34-17) \mathrm{nm}$, and higher volume percent of particle size was $22 \mathrm{~nm}$.

\subsubsection{XRD Results}

The X-Ray Diffraction (XRD) characterization of the silica sand is represented in table (3). 
Table 3. XRD Characterization of Silica nanoparticles.

\begin{tabular}{|l|l|l|}
\hline Oxide & $\mathrm{SiO}_{2 \text { ch }}$ & $\mathrm{SiO}_{2 \text { ph }}$ \\
\hline $\mathrm{SiO}_{2} \mathrm{wt}^{\circ} \%$ & 96 & 87.5 \\
\hline $\mathrm{Al}_{2} \mathrm{O}_{3} \mathrm{wt} \%$ & 2.7 & 9.1 \\
\hline $\mathrm{TiO}_{2} \mathrm{wt}^{\%} \%$ & 0.7 & 1.6 \\
\hline $\mathrm{CaO} \mathrm{wt}^{\%}$ & 0.4 & 1.5 \\
\hline $\mathrm{fe}_{2} \mathrm{O}_{3} \mathrm{wt}^{\%} \%$ & 0.2 & 0.4 \\
\hline
\end{tabular}

As shown from the results, we can clearly see that the silica percent increased with using the chemical method to $(96 \%)$ in comparison with $(87.5 \%)$ obtained with physical methods. On the other hand metallic impurities $\mathrm{Al}_{2} \mathrm{O}_{3}$, $\mathrm{TiO}_{2}, \mathrm{CaO}$, and $\mathrm{fe}_{2} \mathrm{O}_{3}$ contents have been decreased with using chemical method, for example $\left(\mathrm{TiO}_{2}\right)$ slumped from $(1.6 \%)$ to $(0.7 \%)$ with physical method. A surprising result is the existence of aluminum oxide $\mathrm{Al}_{2} \mathrm{O}_{3}$ in the sample, it can be caused by the impurity during grinding process by mortar or during the heat treatment process (the residue of another samples). These results are in good agreement with the results obtained by Wahyudia et al. [9].

\subsubsection{FTIR Results}

The main physicochemical characteristics of extracted silica are identified by Fourier Transform Infrared Spectroscopy (FT-IR). Figure (4) show the Fourier Transform Infrared Spectroscopy (FTIR) results of prepared nanosilica by chemical and physical methods.

(a)

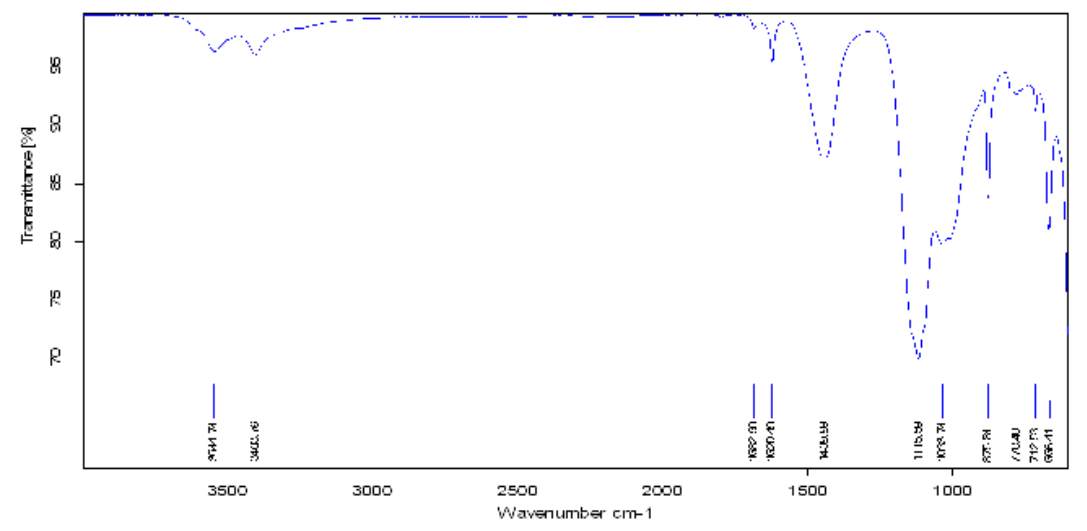

(b)

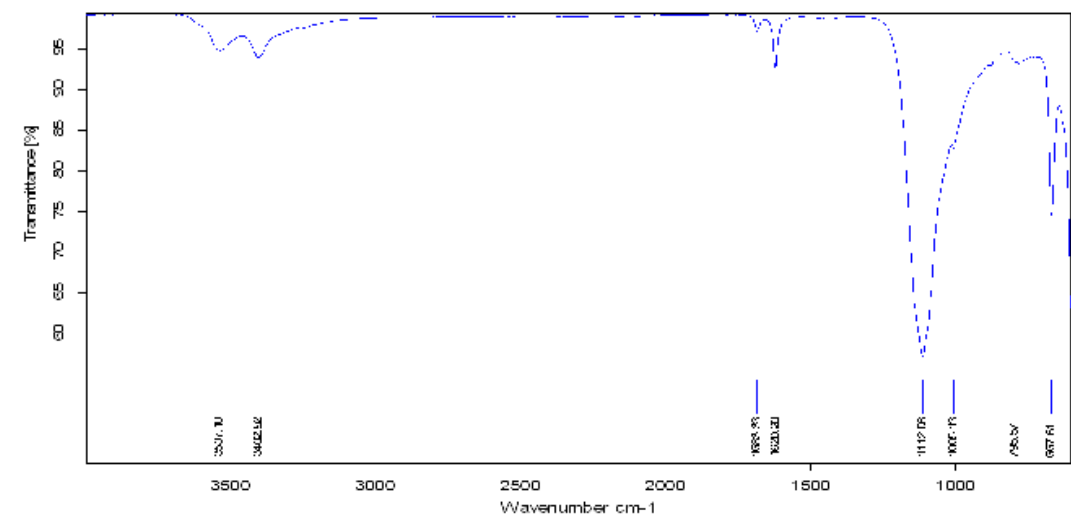

Figure 4. Fourier Transform Infrared Spectroscopy (FTIR) of prepared nanosilica by (a) chemical method and (b) physical method. 
From above figures we noted that, the bands existence at $\left(666.41 \mathrm{~cm}^{-1}\right.$ and $875.84 \mathrm{~cm}^{-1}$ for $\left.\left(\mathrm{SiO}_{2}\right)_{\mathrm{ch}}\right)$ and at $(667.61$ $\mathrm{cm}^{-1}$ and $795.57 \mathrm{~cm}^{-1}$ for $\left.\left(\mathrm{SiO}_{2}\right)_{\mathrm{ph}}\right)$ was becouse the existence of symmetric siloxane groups $v_{\mathrm{s}}(\mathrm{Si}-\mathrm{O}-\mathrm{Si})$. The presence of a band at $1033.74 \mathrm{~cm}^{-1}$ for $\left(\mathrm{SiO}_{2}\right)_{\mathrm{ch}}$ and at $1005.13 \mathrm{~cm}^{-1}$ for $\left(\mathrm{SiO}_{2}\right)_{\mathrm{ph}}$ is associated with $(\mathrm{Si}-\mathrm{OH})$ groups. The shoulder appeared at $3544.74 \mathrm{~cm}^{-1}$ for $\left(\mathrm{SiO}_{2}\right)_{\mathrm{ch}}$ and $3537.18 \mathrm{~cm}^{-1}$ for $\left(\mathrm{SiO}_{2}\right)_{\mathrm{ph}}$, indicating the existence bonds of hydrogen that resulted from silanol groups $(\mathrm{Si}-\mathrm{OH})$ interaction at the nanosilica material surface. [11] The band located at $1439.99 \mathrm{~cm}^{-1}$ for $\left(\mathrm{SiO}_{2}\right)_{\mathrm{ch}}$ and $1620.20 \mathrm{~cm}^{-1}$ for $\left(\mathrm{SiO}_{2}\right)_{\mathrm{ph}}$ is attributed to the vibration of $(\mathrm{O}-\mathrm{H})$ bending of the molecular water adsorbed and its corresponding vibration at $3403.76 \mathrm{~cm}^{-1}$ for $\left(\mathrm{SiO}_{2}\right)_{\mathrm{ch}}$ and $3402.92 \mathrm{~cm}^{-1}$ for $\left(\mathrm{SiO}_{2}\right)_{\mathrm{ph}}$. These results are agree with the results obtained by Rahman et al. [11].

\subsection{Effect of Nanoparticles Addition to Crude Oil}

\subsection{1 $\mathrm{SiO}_{2}$ Nanoparticles Concentration Effect}

The $\mathrm{SiO}_{2}$ Nanoparticles was used to study the influence of concentration on the viscosity of the crude oil matrix. Four concentration $(250,500,1000$ and $1250 \mathrm{mg} / \mathrm{L})$ of $\left(\mathrm{SiO}_{2}\right)_{\mathrm{ph}}$ and $\left(\mathrm{SiO}_{2}\right)_{\mathrm{ch}} \mathrm{NPs}$ were used. The silica nanoparticles had a great affinity for the asphaltenes and heavy compounds in oil, reducing the asphaltenes aggregates size present in the crude oil matrix. As a results the oil viscosity will reduced. Figures (5) and (6) show the effect of $\mathrm{SiO}_{2 \mathrm{ph}}$ and $\mathrm{SiO}_{2 \mathrm{ch}}$ nanoparticles concentration in reducing the viscosity of crude oils at temperatures $(5,10,15,20,25,30,35,40,45,50$ and 60$){ }^{\circ} \mathrm{C}$.

a

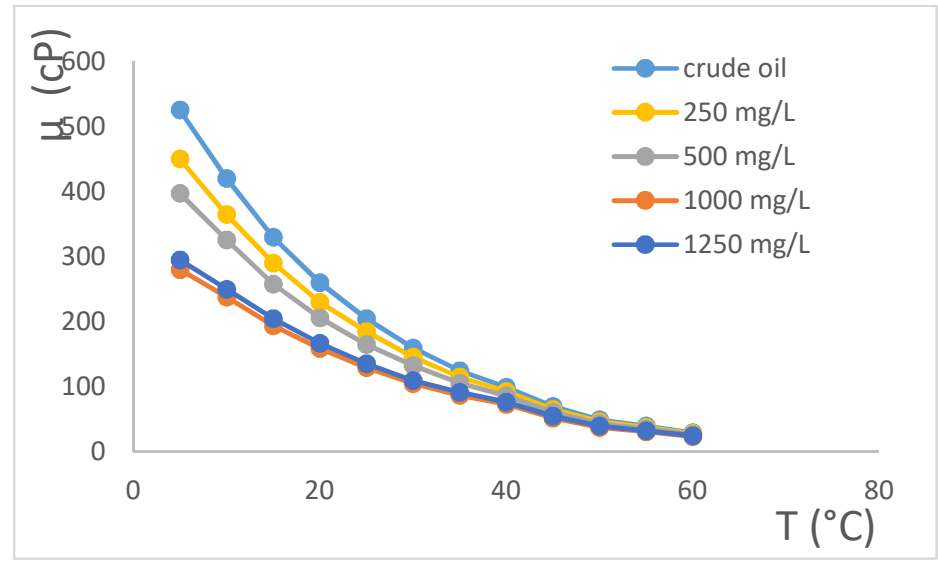

b

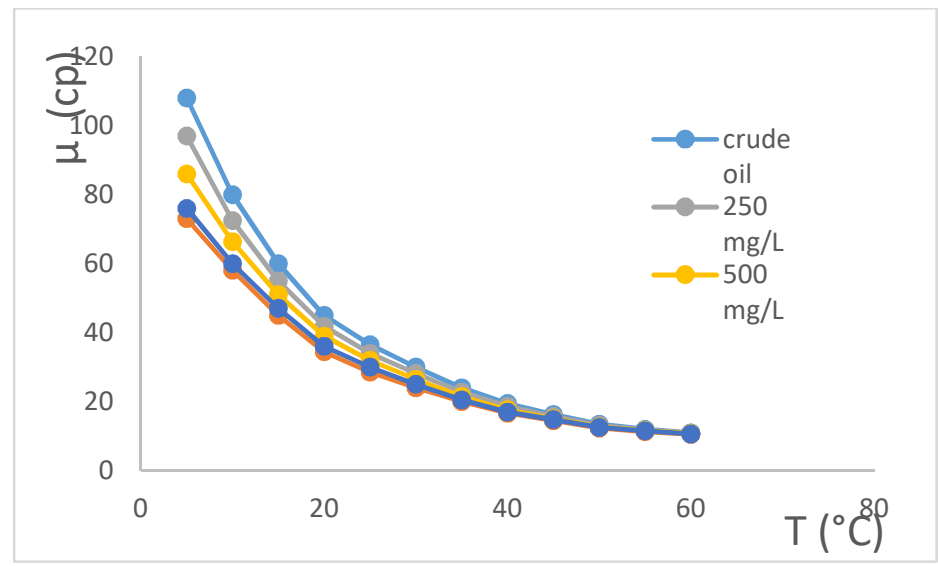

Figure (5): The effect of $\mathrm{SiO}_{2 \text { ph }}$ nanoparticle concentration in reducing the viscosity of (a) $\mathrm{C}_{1}$ and (b) $\mathrm{C}_{2}$ 


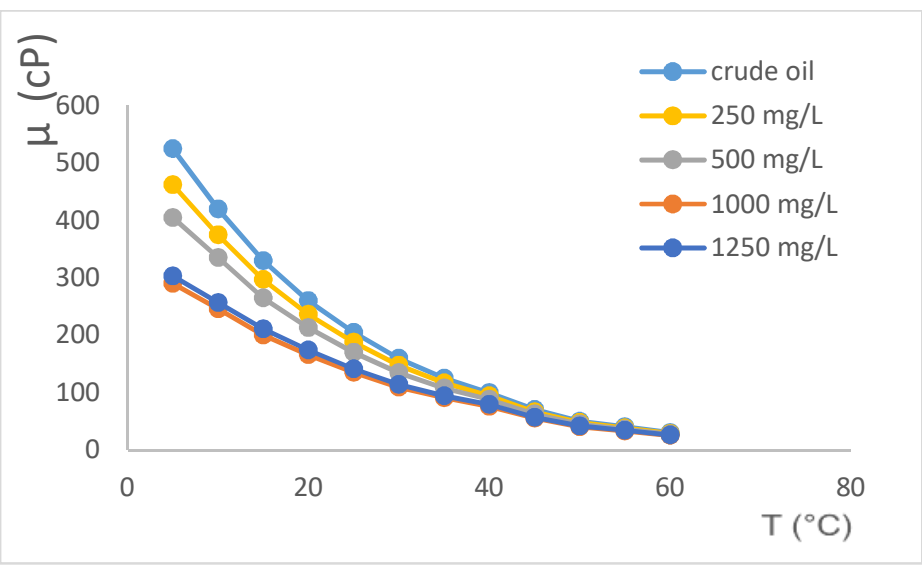

b

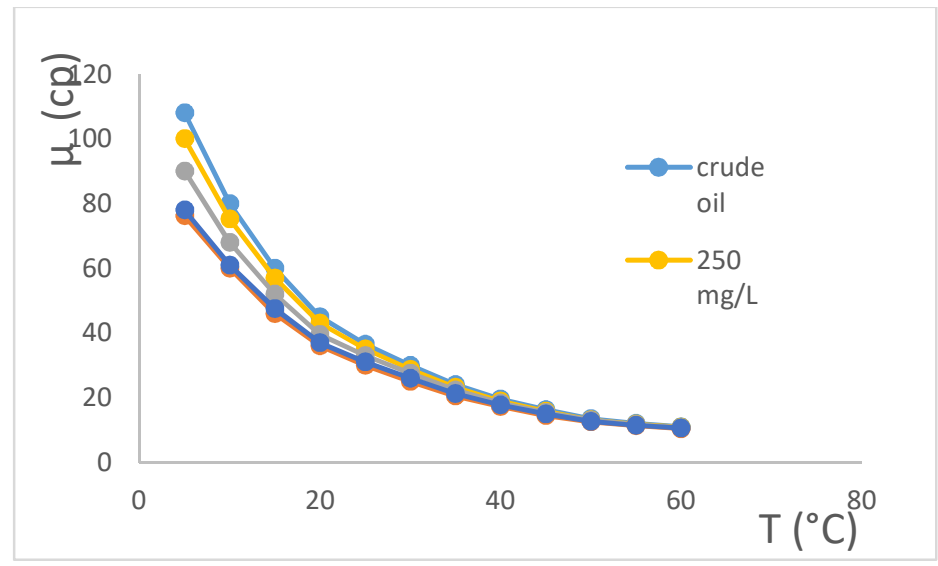

Figure (6): The effect of $\mathrm{SiO}_{2}$ ch nanoparticle concentration in reducing the viscosity of (a) $\mathrm{C}_{1}$ and (b) $\mathrm{C}_{2}$

It was noted that by the addition of nanoparticles in the medium, the viscosity of crude oil tends to decrease with increasing of nanoparticles concentration. This occurs up to the optimal concentration (concentration at which maximum viscosity reduction is achieved) of $1000 \mathrm{mg} / \mathrm{L}$ is reached, this agree with that found by other studies [12-15]. For a concentration of $1250 \mathrm{mg} / \mathrm{L}$ the viscosity reduction still occurs, though smaller compared to the optimal concentration. This might be due to an increase in the packing factor of the particles, which can cause nanoparticles aggregation and clustering which will increase its size [16]. It is worth mentioning that the reduction in viscosity occurs mainly by changes in the structure of asphaltenes in the crude oil. It was concluded that the nanoparticles will adsorb mainly the heavy components of the crude oil to produce a reduction in the asphaltenes aggregates size [14]. The formation of large asphaltene aggregates in solution is inhibited in the presence of nanoparticles, as the adsorption on the nanoparticle hinders or changes the growth of asphaltene aggregate. The same explanation was given by [12, 15 and 14]. When the particles are smaller, more points of contact between asphaltenes and particles will exist, compared to larger particle sizes due to the larger specific surface area [13]. The viscosity of crude oil changes non-monotonically (non-smooth behavior) with increase in the concentration of nanoparticles. The reason of this change is there are many factors affected their behavior such as, nanoparticle - nanoparticle interactions and nanoparticle - heavy compounds interactions yields a somewhat counterintuitive response as these effects may not act in similar fashions. In addition, the rheological characteristics of the fluid prevent a monotonical change in viscosity with increasing concentration of nanoparticles.

\subsubsection{Effect of Temperature on the Degree of Viscosity Reduction Percentage (DVR \%).}

The temperature value at which any fluid is in liquid state plays a key role in processes involving fluid motion. It is important to mention here that the temperature effect is very important in petroleum transportation via pipelines in summer and winter over the year. Although several papers in the specialized literature report viscosity reduction 
using nanoparticles, these mainly study viscosity measurement at only two or three temperatures [15, 17]. Research involving viscosity reduction at more than three temperatures are few, and many lack a phenomenological explanation. Therefore, the present work focus on covering all the ranges of temperatures at which the petroleum is transported (especially pumping conditions in Iraq). The viscosity is measured at twelve temperatures ranged from $5{ }^{\circ} \mathrm{C}$ to $60^{\circ} \mathrm{C}$ with $5{ }^{\circ} \mathrm{C}$ step. The degree of viscosity reduction percentage (DVR \%) was choose to be a good indicator to express the percentage of viscosity reduction with temperature [18]. The (DVR) is defined and calculated by:

$D V R \%=\frac{\mu p-\mu N f}{\mu H O} \times 100 \%$

Where, $\mu_{p}$ and $\mu_{N f}$ are the parent crude oil and nanofluid viscosity values respectively measured in (cP)

a

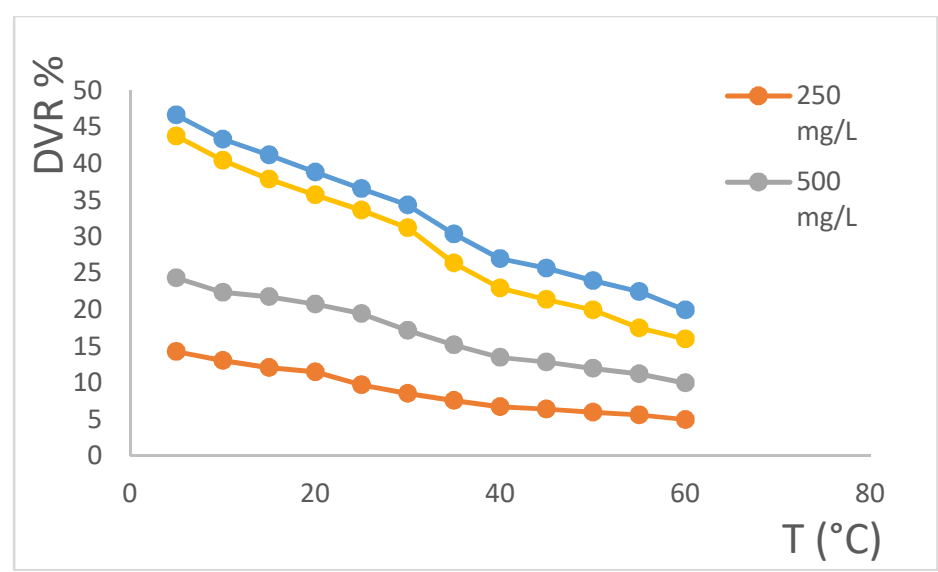

$\mathrm{b}$

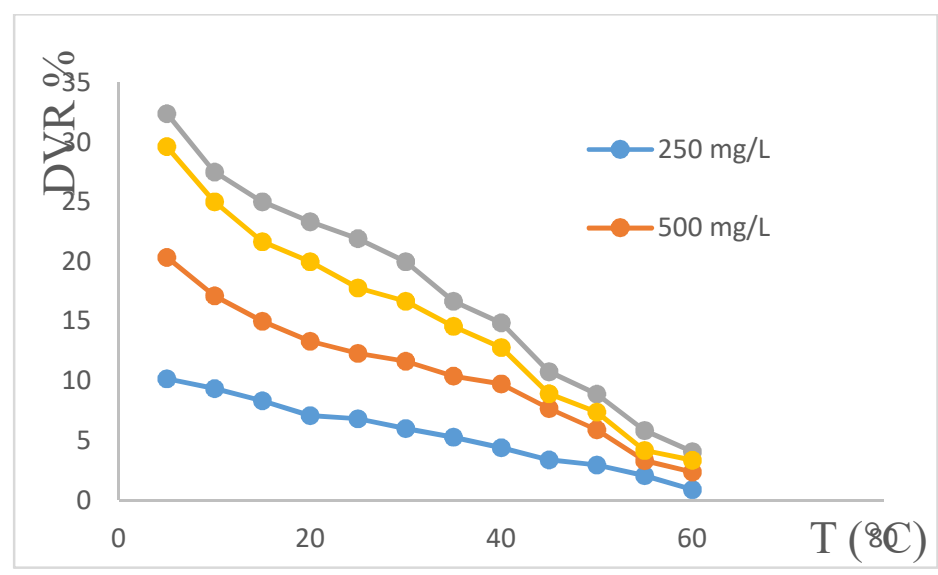

Figure 7. The effect of temperature on DVR \% for (a) $\mathrm{C}_{1}$ and (b) $\mathrm{C}_{2}$ at different concentration of $\mathrm{SiO}_{2 \mathrm{ph}} \mathrm{NPs}_{\text {. }}$ 


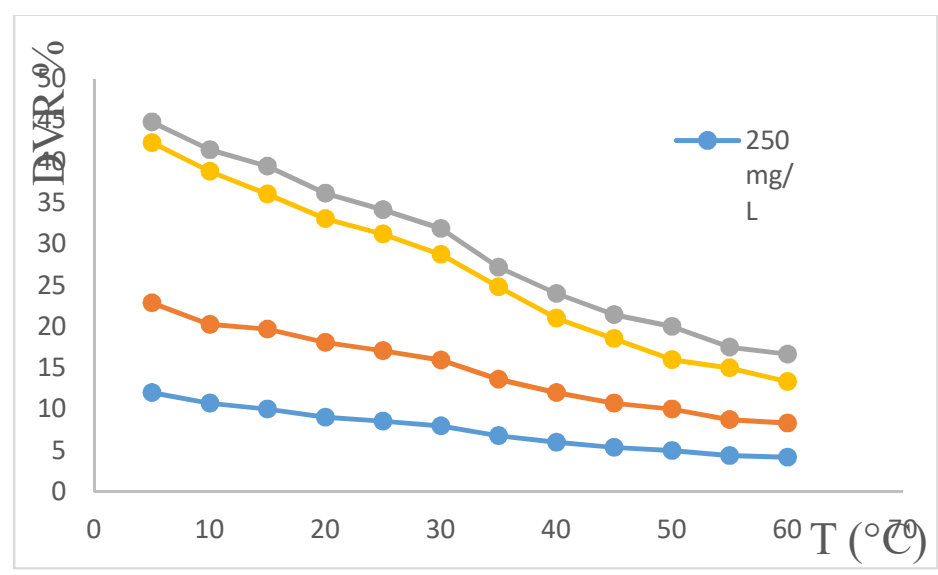

b

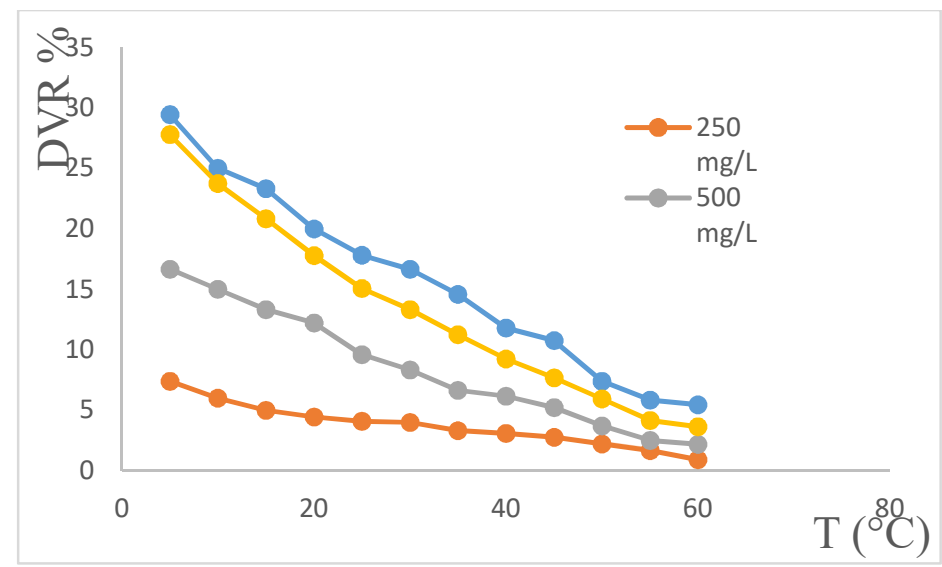

Figure 8. The effect of temperature on DVR \% for (a) $\mathrm{C}_{1}$ and (b) $\mathrm{C}_{2}$ at different concentration of $\mathrm{SiO}_{2 \mathrm{ch}} \mathrm{NP}$.

From these figures it was noted that the DVR \% is very affected by the addition of $\mathrm{SiO}_{2} \mathrm{NPs}_{\text {sith }}$ the higher value of about $46.66 \%$ of $\mathrm{C}_{1}$ with $\mathrm{SiO}_{2 \mathrm{ph}}$ at $1000 \mathrm{mg} / \mathrm{L}$ addition and $5{ }^{\circ} \mathrm{C}$. The viscosity decreases when the temperature increases. Such behavior is agree with that found previously $[18,8]$. Also, it was noted that the performance of nanoparticles in reduction of viscosity of crude oil is much better at cold conditions and reduced with increasing temperature especially at temperatures greater than $40{ }^{\circ} \mathrm{C}$. For example, DVR $\%$ of $\mathrm{C}_{1}$ with $1000 \mathrm{mg} / \mathrm{L}$ of SiO $2 \mathrm{ph}$ at $5{ }^{\circ} \mathrm{C}$ is $46.66 \%$ and at $60{ }^{\circ} \mathrm{C}$ is $20.02 \%$. This happens as a result of natural changes in the reference values (the viscosity of parent crude oil). The other reason of this behavior is the asphaltene adsorption onto nanoparticles is exothermic process. The temperature is strongly related with the size of the asphaltene aggregates. As the temperature increases, the aggregates size decreases, and then the adsorption capacity decreases. As the DVR is calculated as a percentage, it is expected that at a lower temperature, the viscosity change is greater compared to generated at higher temperatures. The values of DVR \% shows that the best performance of nanoparticles at which the greatest change in viscosity occurs is at $5{ }^{\circ} \mathrm{C}$ and the worst at $60{ }^{\circ} \mathrm{C}$. It worth to mention that the viscosity decreases when attractive binding energy is reduced, the reason is the reduction in the cohesive forces of the crude oil molecular components. At low temperatures, some components of the crude oil behave as solids and the system viscosity would depend on their breakage or alignment, these conclusions are agree with [19].

\subsubsection{Effect of oil Composition.}

The API gravity play an important role in determining the flow behavior of crude oil. Then, the heavier crude oil with the higher value of asphaltene is the more viscous. Therefore, the nanoparticles will work to reduce the asphaltene content and the viscosity will be improved. In the present work, two different crude oils with API gravities $17.4^{\circ}$ and $29.1^{\circ}$ are used to evaluate the effect of oil composition on performance of silica nanoparticles in viscosity reduction. 

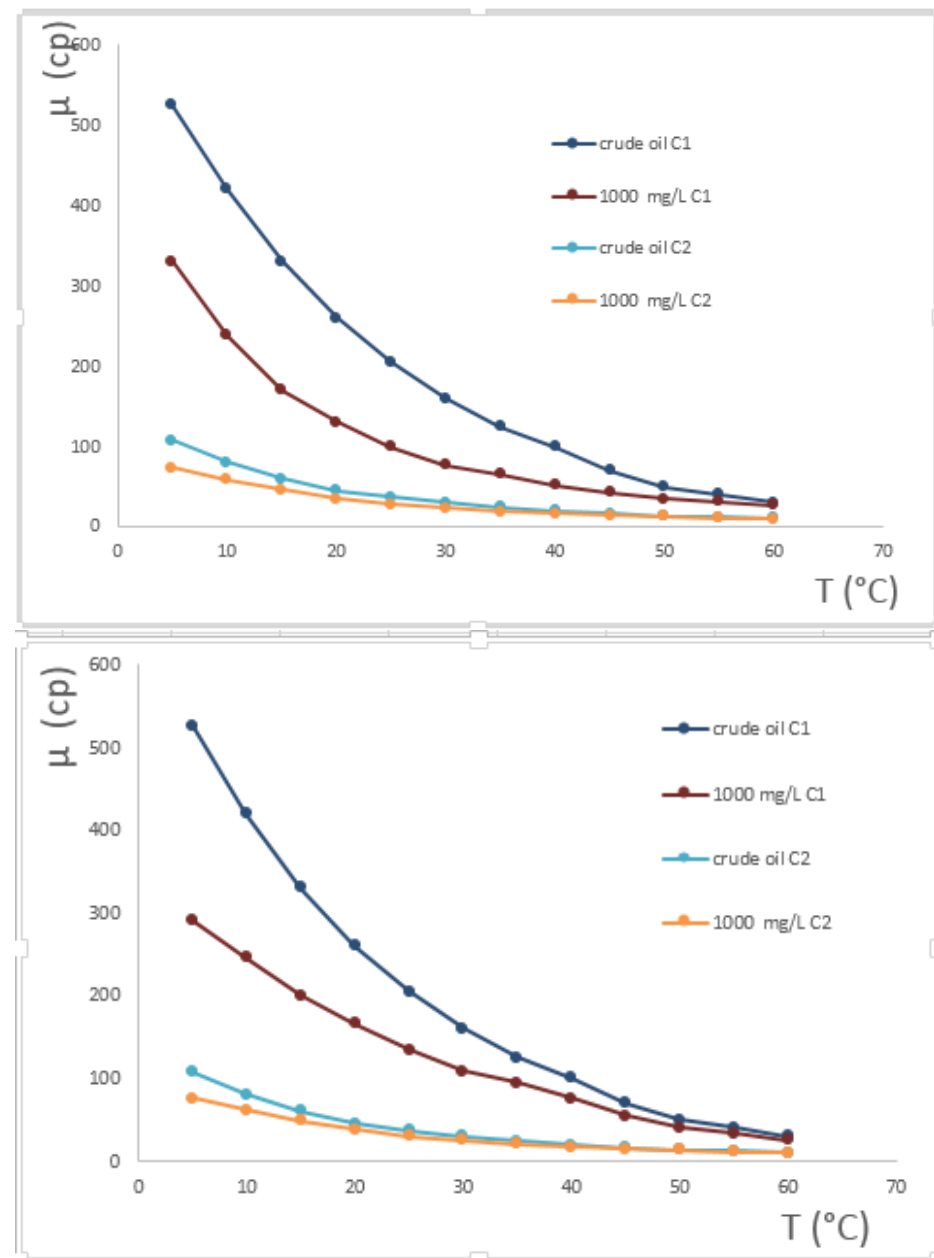

Figure 9. Comparison between the viscosity of different crude oils with and without (a) $\mathrm{SiO}_{2 \mathrm{ph}}$ and (b) $\mathrm{SiO}_{2 \mathrm{ch}}$ NPs addition at concentration of $1000 \mathrm{mg} / \mathrm{L}$ and temperatures between $5^{\circ} \mathrm{C}$ and $60^{\circ} \mathrm{C}$.

The heavier crude oils exhibits viscosity values much higher than the lighter ones at all temperatures. This is mainly due to a high content of asphaltenes and a substantial decline in the API gravity. It was observed that the $\mathrm{SiO}_{2} \mathrm{NPs}$ have similar behavior in both crude oils, interacting with asphaltene aggregates, altering their colloidal structure and generating a significant reduction in the viscosity. On the other hand, the silica nanoparticles are more effective to lowering viscosity in high API gravity crude oils. Where, the reduction in viscosity of crude oil $\mathrm{C}_{1}$ is much higher than the crude oil $\mathrm{C}_{2}$ especially at low temperatures. For example at $5{ }^{\circ} \mathrm{C}$ and $1000 \mathrm{mg} / \mathrm{L}$ of $\mathrm{SiO}_{2 \mathrm{ph}} \mathrm{DVR} \%$ of $\mathrm{C}_{1}$ is $46.66 \%$ while for $\mathrm{C}_{2}$ is $32.407 \%$.

3.2.4 Nanoparticles Production Method (Physical and Chemical) Effect In this work, the silica nanoparticles was produced by two methods (chemical and physical) and the produced types of NPs have different specifications such as, chemical composition, particle size, surface area etc. Therefore, there effect in crude oil viscosity reduction already will different. 


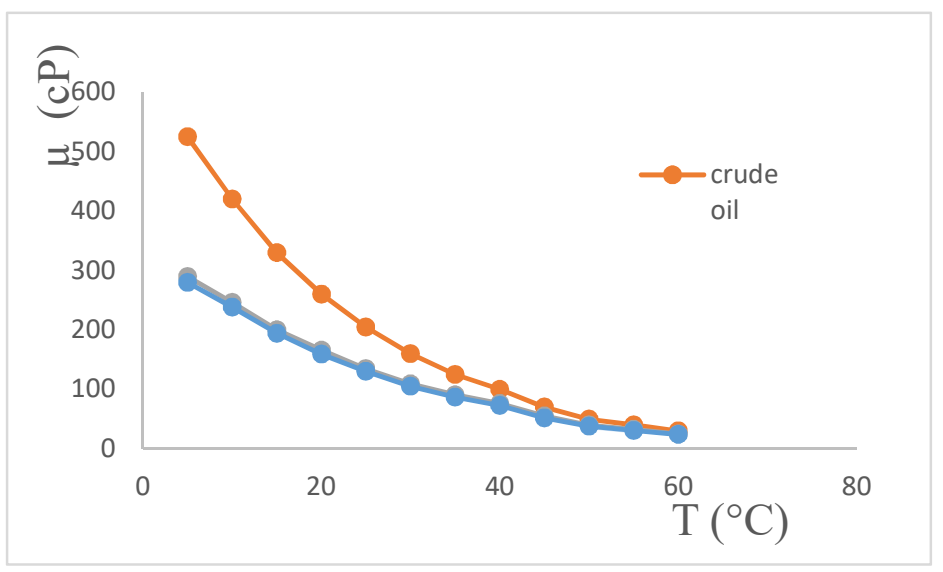

b

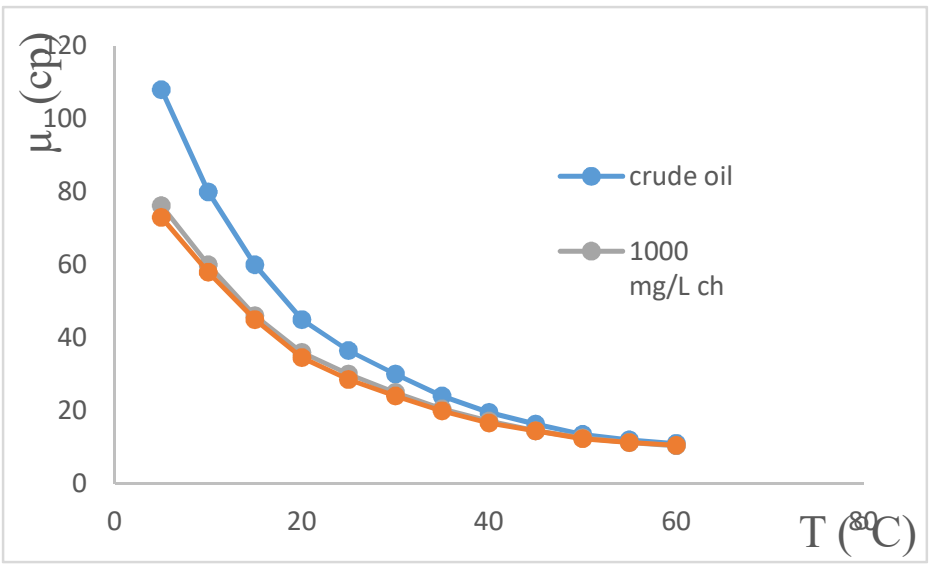

Figure (10): The relationship between viscosity and temperatures for (a) $C_{1}$ and (b) $C_{2}$ with $1000 \mathrm{mg} / \mathrm{L}$ of $\left(\mathrm{SiO}_{2 \mathrm{ph}}\right.$ and $\left.\mathrm{SiO}_{2 \mathrm{ch}}\right)$ additions.

The comparison is basis on the best concentration of NPs of $1000 \mathrm{mg} / \mathrm{L}$. It was observed from these figures that the $\mathrm{SiO}_{2 \mathrm{ph}}$ shows slightly higher effect on viscosity reduction in comparison with $\mathrm{SiO}_{2 \text { ch. }}$.

This attributed to high surface area of $\mathrm{SiO}_{2 \mathrm{ph}}\left(705 \mathrm{~m}^{2} / \mathrm{g}\right)$ that possess smallest particle size of $(22 \mathrm{~nm})$ in comparison with $\left(520 \mathrm{~m}^{2} / \mathrm{g}\right)$ surface area and $(35 \mathrm{~nm})$ particle size for $\mathrm{SiO}_{2 \mathrm{ch}}$. Since at a fixed concentration, there is a larger number of individual nanoparticles interacting with asphaltene aggregates, which increases the contact area and tends to further fragmentation of these hydrocarbons. The same results were noted by [14].

From these results, it was concluded that the viscosity reduction in the crude oil increases as nanoparticle size decreases.

Many authors [20-22] pointed that the surface area of nanoparticles is very important factor and will be contributed in determine the final specifications of nanofluid.

\subsection{Addition of Nanoparticles to Diesel (Not Have Asphaltenes Content in Its Structure)}

An additional test was performed to evaluate the performance of $\left(\mathrm{SiO}_{2 \mathrm{ph}}\right.$ and $\left.\mathrm{SiO}_{2 \mathrm{ch}}\right)$ nanoparticles in the Diesel fuel (as a base fluid) which don't have asphaltene content. The temperatures $\left(15^{\circ} \mathrm{C}\right.$ and $\left.40{ }^{\circ} \mathrm{C}\right)$ were selected to expression for summer and winter pumping conditions (especially in Iraq). The aim of this test is to prove that the nanoparticles require interaction as well as asphaltenes to reduce the oil viscosity. 


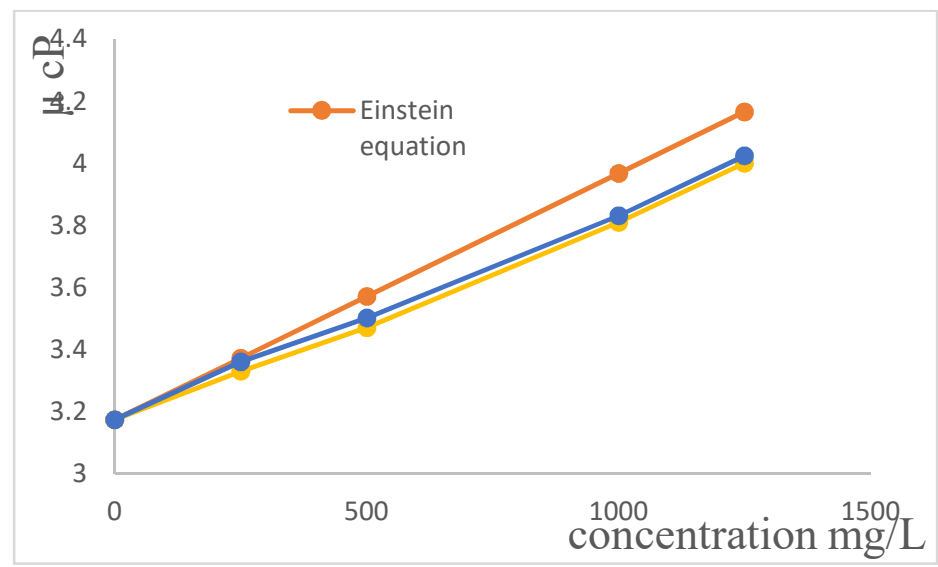

b

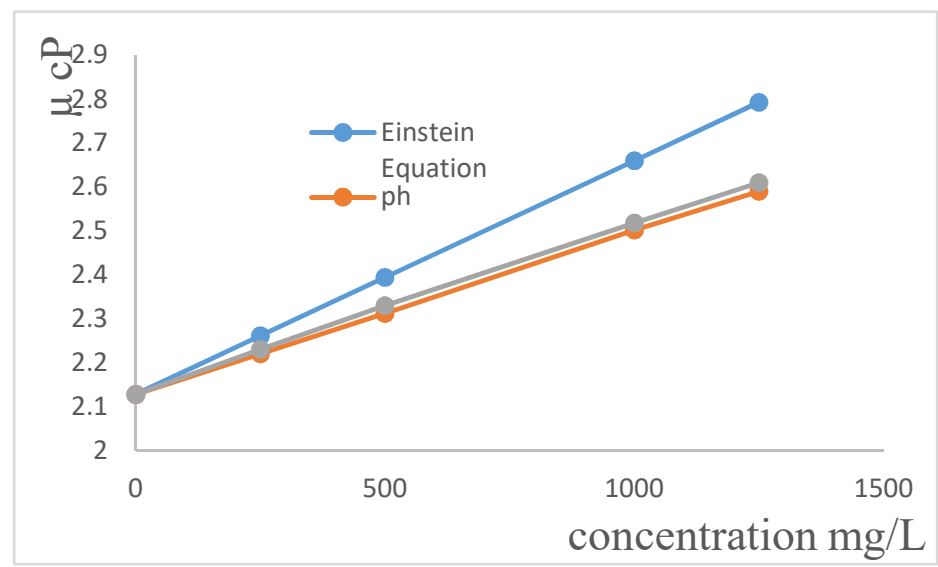

Figure (11): The effect of $\left(\mathrm{SiO}_{2 \mathrm{ph}}\right.$ and $\left.\mathrm{SiO}_{2 \mathrm{ch}}\right) \mathrm{NPs}$ on viscosity of diesel fuel at various concentrations and temperatures of (a) $15{ }^{\circ} \mathrm{C}$ and (b) $40^{\circ} \mathrm{C}$.

From these results, it was concluded that by addition of nanoparticles to the diesel, the viscosity is increased with increasing nanoparticles concentration for both types of nanoparticles and at all temperatures, the same conclusion was given by [12]. The diesel in the absence of nanoparticles have a value of viscosity of $3.174 \mathrm{cP}$ at $15^{\circ} \mathrm{C}$ and $2.128 \mathrm{cP}$ at $40^{\circ} \mathrm{C}$. The largest change in viscosity occurs with the addition of $1250 \mathrm{mg} / \mathrm{L}$. For example at $15^{\circ} \mathrm{C}$, the viscosity became $3.864 \mathrm{cP}$ with $\mathrm{SiO}_{2 \mathrm{ch}}$ and $3.84 \mathrm{cP}$ with $\mathrm{SiO}_{2 \mathrm{ph}}$. At this concentration for an increase of $27.801 \%$ of $\mathrm{SiO}_{2 \mathrm{ch}}$ and $26.969 \%$ of $\mathrm{SiO}_{2 \mathrm{ph}}$ regarding the oil without nanoparticles. These results are agree with [12]. This increasing in viscosity due to lack of interactions between asphaltenes and the solid particles that remain dispersed in the liquid, contrary to what happens in a crude oil with high asphaltene content. When $1000 \mathrm{mg} / \mathrm{L}$ of silica nanoparticles were added at $15{ }^{\circ} \mathrm{C}$, the viscosity increases by roughly $21.742 \%$ for $\mathrm{SiO}_{2 \mathrm{ch}}$ and $20.983 \%$ for $\mathrm{SiO}_{2 \mathrm{ph}}$. Also, it was observed that the $\mathrm{SiO}_{2 \mathrm{ch}} \mathrm{NPs}$ increase the viscosity of diesel larger than $\mathrm{SiO}_{2 \mathrm{ph}}$. This attributed to the sizes of these particles. Where, the particles size of $\mathrm{SiO}_{2 \mathrm{ch}}$ is larger than the $\mathrm{SiO}_{2 \text { ph }}$ particles size. Many authors found that the particle size of nanoparticles is has important effect on the nanofluids viscosity [23, 24]. This result is consistent with expectations of the theory of hydrodynamic viscosity of Einstein [25] which proposes that the effective viscosity of suspension increases linearly with increasing solid volume fraction and is always greater than the viscosity of carrier fluid. Mathematically, this correlation is provided as,

$\mu=\mu_{0}[1+2.5 \phi]$ 
Where,

$\mu$ is viscosity of suspension, $\mu_{0}$ is viscosity of carrier fluid and $\phi$ is volume fraction of dispersed particles.

Einstein's equation is not highly accurate for nanoparticle additions, because this equation do not take into consideration the size of solid particles, Brownian motion, packing factor and other factors affect the nanofluid viscosity [26]. From these results it can be stated that the nanoparticles are able to reduce oil viscosity when there is an asphaltene in the structure oil.

\section{Conclusions}

From this work, the following main conclusions are drawn:

1. Nano-silica was successfully obtained by two methods (physical and chemical) with average particle size of 30 $\mathrm{nm}$ and $45 \mathrm{~nm}$ for $\mathrm{SiO}_{2 \mathrm{ph}}$ and $\mathrm{SiO}_{2 \mathrm{ch}} \mathrm{NPs}$ respectively.

2. The XRF results of silica nanoparticles show the purity of $\mathrm{SiO}_{2 \text { ch }}$ about $96 \%$ while for $\mathrm{SiO}_{2 \text { ph }}$ about $87 \%$.

3. The Result of the present work show that $\mathrm{SiO}_{2 \mathrm{ph}}$ nanoparticles have a higher surface area compared to the $\mathrm{SiO}_{2 \mathrm{ch}}$ nanoparticles.

4. The results of this research provide a phenomenological explanation for the viscosity reduction of crude oil by the addition of solid nanoparticles, towards industrial applications to optimize the conditions of mobility and transport and thus provide a path for new technologies that produce saving economic, energy and good technical performance.

5- The results showed that the silica nanoparticles have great effect on the reduction of crude oil viscosity reach to about $46.66 \%$.

6- The optimal concentration of nanoparticles found to be $1000 \mathrm{mg} / \mathrm{L}$ at which maximum viscosity reduction is achieved at all temperatures tested.

7- It was concluded that the performance of nanoparticles in crude oil viscosity reduction at low temperatures is much better than at high temperatures.

8- The results shows that the performance of $\mathrm{SiO}_{2 \text { ph }}$ in viscosity reduction is slightly higher than $\mathrm{SiO}_{2 \text { ch. }}$

9- It was concluded that when the nanoparticles added to the hydrocarbons have not asphaltene content in their structure the viscosity will increase which in turn proves the reason of reduction in viscosity in crude oil.

\section{References}

[1] Yousef Al-Roomi, Reena George, Ahmed Elgibaly and Ali Elkamel. Use of a novel surfactant for improving the transportability/ transportation of heavy/viscous crude oils. Journal of Petroleum Science and Engineering 42 (2004) 235- 243

[2] Marco A. Farah, Roberto. Oliveira, Jorge Navaes Caldas, and Krishnaswamy Rajagopal. Viscosity of water-inoil emulsions: Variation with temperature and water volume fraction. Journal of Petroleum Science and Engineering 48 (2005) 169- 184.

[3] Mortazavi-Manesh S, Shaw JM. Effect of diluents on the rheological properties of Maya crude oil. Energy Fuels 2016; 30:766-72.

[4] Franco CA, Nassar NN, Ruiz MA, Pereira-Almao P, Cortés FB. Nanoparticles for inhibition of asphaltenes damage: adsorption study and displacement test on porous media. Energy Fuels 2013; 27:2899-907.

[5] Franco CA, Montoya T, Nassar NN, Pereira-Almao P, Cortés FB. Adsorption and subsequent oxidation of colombian asphaltenes onto Nickel and/or Palladium oxide supported on fumed silica nanoparticles. Energy Fuels $2013 ; 27: 7336-47$. 
[6] W. A. Issa. Development of a Nanofluid Pump Test Unit. International Journal of Emerging Technology and Advanced Engineering. Volume 3, Issue 5, May 2013.

[7] Taborda EA, Franco CA, Lopera SH, Alvarado V, Cortés FB. Effect of nanoparticles / nanofluids on the rheology of heavy crude oil and its mobility on porous media at reservoir conditions. Fuel 2016; 184:222-32.

[8] Zabala R, Franco CA. Cortes FB. Application of nanofluids for improving oil mobility in heavy oil and extraheavy oil: a field test. Soc Petrol Eng J; 2016:14.

[9] A. Wahyudia, T. Nurasidb, S. Rochania, Preparation of nanoparticle silica from silica sand and quartzite by ultrafine grinding, in: Proceeding of International Conference, 28, 2012, pp. 1-7.

[10] G. Quercia, A. Lazaro, J.W. Geus, H.J.K. Brouwers, Characterization of morphology and texture of several amorphous nano-silica particles used in concrete, Cement Concr. Compos. (2013) 45.

[11] Rahman I A, Vejayakumaran P, Sipaut C S, Ismail J, Chee C K (2009) Size-dependent physicochemical and optical properties of silica nanoparticles. Materials Chemistry and Physics 114:328-332.

[12] Esteban A. Taborda, Vladimir Alvarado, Camilo A. Franco, Farid B. Cortés, Rheological demonstration of alteration in the heavy crude oil fluid structure upon addition of nanoparticles, Fuel, Volume 189, 1 February 2017, Pages 322-333

[13] Taborda EA, Franco CA, Ruiz MA, Alvarado V, Cortés FB. Experimental and theoretical study of viscosity reduction in heavy crude oils by addition of nanoparticles. Energy Fuels 2018; 31:1329-38.

[14] Nassar NN, Betancur S, Acevedo S, Franco CA, Cortés FB. Development of a population balance model to describe the influence of shear and nanoparticles on the aggregation and fragmentation of asphaltene aggregates. Ind Eng Chem Res 2015; 54:8201-11.

[15] Esteban A. Taborda, Vladimir Alvarado, Farid B. Cortés. Effect of $\mathrm{SiO}_{2}$ based nanofluids in the reduction of naphtha consumption for heavy and extra-heavy oils transport: Economic impacts on the Colombian market. Energy Conversion and Management 148 (2017) 30-42

[16] Sezer Özerinç. M.Sc. Thesis. Heat Transfer Enhancement with Nanofluids. School of Natural and Applied Sciences of Middle East Technical University. 2010.

[17] Franco CA, Lozano MM, Acevedo S, Nassar NN, Cortés FB. Effects of resin I on asphaltene adsorption onto nanoparticles: a novel method for obtaining asphaltenes/resin isotherms. Energy Fuels 2015; 30:264-72.

[18] Hasan SW, Ghannam MT, Esmail N. Heavy crude oil viscosity reduction and rheology for pipeline transportation. Fuel 2010; 89:1095-100.

[19] Mortazavi-Manesh S, Shaw JM. Thixotropic rheological behavior of Maya crude oil. Energy Fuels 2014; 28:972-9. Abivin P, Taylor SD, Freed D. Thermal behavior and viscoelasticity of heavy oils. Energy Fuels 2012; 26:3448-61.

[20] Nashaat N. Nassar, Azfar Hassan, and Pedro Pereira-Almao. Effect of the Particle Size on Asphaltene Adsorption and Catalytic Oxidation onto Alumina Particles. Energy Fuels 2011, 25, 3961-3965.

[21] Stefania Betancur, Juan C Carmona, Nashaat N. Nassar, Camilo A. Franco, and Farid B. Cortés. Role of Particle Size and Surface Acidity of Silica Gel Nanoparticles in Inhibition of Formation Damage by Asphaltene in Oil Reservoirs. Industrial \& Engineering Chemistry Research. 2016.

[22] Yousef Hamedi Shokrlu, Tayfun Babadagli, Viscosity reduction of heavy oil/bitumen using micro and nano metal Particles during aqueous and non-aqueous thermal applications, Journal of Petroleum Science and Engineering, 2014.05.012

[23] Halil Dogacan Kocaa, Serkan Doganayb, Alpaslan Turgutc, Ismail Hakki Tavmanc, R. Saidurd,e, Islam Mohammed Mahbubulf. Effect of particle size on the viscosity of nanofluids: A review. Renewable and Sustainable Energy Reviews 82 (2018) 1664-1674.

[24] V.Ya.Rudyak, S.L.Krasnolutskii. Dependence of the viscosity of nanofluids on nanoparticle size and material. Physics Letters A 378 (2014) 1845-1849.

[25] Einstein A. Eine neue bestimmung der moleküldimensionen. Ann Phys 1906; 324:289-306.

[26] Harshkumar Patel. M.Sc. Thesis. Effect of Nanoparticles and Solvent Based Emulsion on Heavy Oil Viscosity. Mewbourne School of Petroleum and Geological Engineering, University Of Oklahoma. 2016. 